\title{
An improved micropropagation protocol for stone pine (Pinus pinea L.)
}

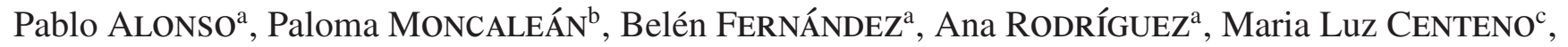 \\ Ricardo J. ORDÁs ${ }^{a *}$ \begin{abstract}
C/ Catedrático Rodrigo Uría s/n, 330071 Oviedo, Spain
${ }^{\mathrm{b}}$ Current adress: Instituto Vasco de Investigación y Desarrollo Agrario, Centro Arkaute, Aptdo. 46, 01080 Vitoria-Gasteiz, País Vasco, Spain
\end{abstract} \\ a Área de Fisiología Vegetal, Instituto Universitario de Biotecnología, Departamento de Biología de Organismos y Sistemas, Universidad de Oviedo, \\ ${ }^{c}$ Departamento de Biología Vegetal, Universidad de León, Facultad de Ciencias Biológicas y Ambientales, Campus de Vegazana, León, Spain
}

(Received 9 November 2005; accepted 30 May 2006)

\begin{abstract}
A protocol for micropropagation from isolated cotyledons from Pinus pinea L. has been developed. Major improvements are the increase in rooting rates and the description for the first time of a successful continuous multiplication procedure. For bud induction, isolated cotyledons were cultured on $1 / 2 \mathrm{LP}$ with $44.4 \mu \mathrm{M}$ BA during 4 days. Shoot development was obtained by transfer to $1 / 2$ LP hormone-free medium with activated charcoal. Since an additional 20 weeks were required for shoot elongation and rooting, at least 70 plantlets can be expected per seed after 29 weeks based on a $70 \%$ success rate. Besides, shoots can be micropropagated successively by subculturing on $1 / 2$ LPC.
\end{abstract}

conifers / micropropagation / organogenesis / rooting / tissue culture

Résumé - Amélioration du protocole de multiplication par micropropagation du pin pignon (Pinus pinea L.). Nous avons développé un protocole de multiplication par micropropagation de Pinus pinea L. à partir de cotylédons isolés. Les principaux progrès réalisés concernent l'augmentation du taux d'enracinement et la description pour la première fois d'une méthode de multiplication en continu. Pour l'induction des bourgeons, des cotylédons isolés ont été cultivés dans le milieu $1 / 2 \mathrm{LP}$ avec $44.4 \mu \mathrm{M}$ BA pendant 4 jours. Le développement des pousses a été obtenu en transférant les bourgeons dans un milieu $1 / 2$ LP sans hormone avec du charbon actif. Compte tenu des délais nécessaires (20 semaines) pour obtenir l'élongation des pousses et l'enracinement, au moins 70 plantules par graine peuvent être obtenues au bout de 29 semaines, sur base d'un taux d'enracinement de $70 \%$. De plus, les pousses peuvent être multipliées avec succès par micropropagation par sous-culture dans le milieu $1 / 2$ LPC.

conifère / micropropagation / organogenèse / enracinement / culture de tissus

\section{INTRODUCTION}

Stone pine (Pinus pinea L.) is an economically important tree in the Mediterranean area, with an important role in soil conservation, landscape architecture, and is highly regarded for its edible seeds. This makes many aspects of its management similar to an agronomic tree. The existence of a wide potential for improvement and the great economic value of the pine nuts gives good reasons for genetic breeding programs. These programs are based on the identification of excellent genotypes by establishing clonal banks with different provenances. The heritability of seed characters such as length, number per cone and cone weight is high [14]. Hence an improvement in the quantity and quality of seed production per tree is one of the main objectives of the developing programmes in this area. Unfortunately the stone pine pruning possibilities are very limited, as this species does not root as cutting (Luis Gil, personal communication). Grafting is the preferred method to propagate and evaluate genetically indi-

\footnotetext{
*Corresponding author: rordas@.uniovi.es
}

vidual clones. The conventional techniques of asexual propagation present problems for obtaining the best results. In addition, an identical clone implanted on different rootstocks presents an interaction scion-rootstock that leads to certain variability in the results and different productivities (Luis Gil, personal communication). This problem implies finding not only the best scion, but also, the most appropriate rootstock. The limitations of this optimal rootstock present the inconvenience in propagation of certain genotypes already in mature state. Recently, the development of a micrografting protocol could improve the current situation of $P$. pinea breeding programs by reducing its costs and allowing a rapid build-up of plantations for genotype selection trials [5].

In vitro culture offers the possibility to propagate Pinus pinea L. on a large scale, which is difficult by other traditional procedures such as rooting from selected pines. The production of clonal plants from selected seeds of this coniferous species via organogenesis has been thoroughly studied $[4,6,7,14,18]$. The propagation system is based on the induction of shoot buds in cotyledonary explants dissected from stone pine embryos and cultured in the presence of a 
cytokinin (Ck), usually $\mathrm{N}^{6}$-benzyladenine (BA). On the contrary to what has been reported for other pines [9], the presence of auxins in the caulogenic induction media does not improve the efficiency of the organogenic response in stone pine cotyledons [18]. Adventitious bud formation is direct and dependent on the exposure time and concentration of BA in the medium [13]. Age and tissue differentiation of $P$. pinea explants are other determining factors, as shown by the inverse relationship between germination time of the embryos and the shoot-forming ability of their excised cotyledons [19]. Nevertheless, various aspects of the system could be improved, among which a reduction in bud induction period would be particularly beneficial [13]. Moreover, the continuous multiplication had not been established and the rooting process required additional experimentation. Although clonal propagation of stone pine via adventitious bud stimulation from cotyledons was obtained, the very low efficiency of the rooting process $[4,7,18]$ remained the bottleneck of stone pine micropropagation, reducing the possibilities of applying this technique on a usable scale. In this paper, we present an improved plant regeneration method of $P$. pinea that reduces the bud induction time, dramatically increases the rooting rate and for the first time shows a successfully proliferation procedure.

\section{MATERIAL AND METHODS}

\subsection{Explant source and culture conditions}

Embryos from 1-year-old stone pine (Pinus pinea L.) seeds were used. Seeds obtained from selected open-pollinated trees in natural stands were provided by the Servicio de Material Genético of the Ministerio de Medio Ambiente (Spain). All through the experimentation, lots of seeds belonging to 2000, 2001 and 2002 years from Meseta Norte (ES01 region) were used.

After removal of the seed coat, megagametophytes were surface sterilized by immersion in $7.5 \% \mathrm{H}_{2} \mathrm{O}_{2}$ for $45 \mathrm{~min}$, followed by three rinses in sterile double-distilled water. Megagametophytes were then imbibed in moistened sterile paper for $48 \mathrm{~h}$ at $4{ }^{\circ} \mathrm{C}$ in darkness to facilitate dissection of the embryos.

Plant cultures were maintained in a growth chamber at $25 \pm$ $1{ }^{\circ} \mathrm{C}$ with a 16-h photoperiod under a photosynthetic photon flux of $80 \pm 5 \mu \mathrm{mol} \mathrm{m} \mathrm{m}^{-2} \mathrm{~s}^{-1}$ provided by cool white fluorescent tubes (TLD 58 W/33, Philips, France), except where indicated.

\subsection{Bud induction and growth}

After the above mentioned imbibition period, cotyledons (an average of 10 per seed, Fig. 2A) were excised from embryos and horizontally placed in baby jars (ten per jar) containing $20 \mathrm{~mL}$ of bud induction medium, consisting of Le Poivre medium with half strength macroelements $(1 / 2 \mathrm{LP})$, as modified by Aitken-Christie et al. [1], supplemented with $0.8 \%$ (w/v) agar (Roko S.A., A Coruña, Spain), 3\% (w/v) sucrose and cytokinins. The cytokinins assayed were BA, $\mathrm{N}^{6}$-benzyladenosine (9R-BA), $\mathrm{N}^{6}$-isopentenyladenine (iP), $\mathrm{N}^{6}$-isopentenyladenosine (iPR), meta-Topolin (mT), Zeatin $(\mathrm{Z})$ and Zeatin riboside $(\mathrm{ZR})$ at different concentrations $(0.4,1,4.4,10$ or $44.4 \mu \mathrm{M})$. After $35 \mathrm{~d}$ on bud induction medium, the cotyledons were transferred to a hormone free medium $(1 / 2$ LPC) consisting of $1 / 2$ LP supplemented with $0.5 \%(\mathrm{w} / \mathrm{v})$ activated charcoal (AC) (Sigma, Madrid, Spain), 0.8\% (w/v) agar and 3\% (w/v) sucrose according to Humara et al. [8]. Before autoclaving, the $\mathrm{pH}$ of all media was adjusted to 5.8. The explants were subcultured monthly onto the same fresh bud growth medium $(1 / 2$ LPC). After two subcultures $(60 \mathrm{~d})$ on $1 / 2 \mathrm{LPC}$, the percentage of cotyledons forming buds (CFB), number of buds per cotyledons, bud forming capacity index $(\mathrm{BFC}=[\%$ cotyledons forming buds $\times$ average number buds per cotyledon $] / 100$ ) and the shoot elongation capacity $(\mathrm{SEC}=[$ number shoots $>10 \mathrm{~mm} /$ total number shoots per explant] $\times 100$ ) were calculated for all bud induction treatments according to Lopez et al. [9].

\subsection{Shoot development and axillary bud multiplication}

For bud induction, the cotyledons were induced in bud induction medium consisting on $1 / 2$ LP with $44.4 \mu \mathrm{M}$ BA according to Moncaleán et al. [13]. The influence of BA exposure time $(2,4,8,16$ and 35 d) of cotyledons (named C2, C4, C8, C16 and C35) was studied. After two monthly subcultures on $1 / 2$ LPC medium for shoot development from induced buds, the shoots (named S2, S4 and S8 from $\mathrm{C} 2, \mathrm{C} 4$ and $\mathrm{C} 8$ cotyledons) were separated from the cotyledonary explants and elongated by sequential subculturing on shoot growth medium in baby jars for $15 \mathrm{~d}$ followed by subculture to $1 / 2 \mathrm{LPC}$ for $30 \mathrm{~d}$. Shoot growth media tested were $1 / 2$ LPC or a $1 / 2$ LP containing BA $(4.4 ; 0.4$ or $0.04 \mu \mathrm{M})$ alone or $4.4 \mu \mathrm{M}$ BA with indol-butyric acid (IBA), $(0.4,0.04$ or $0.004 \mu \mathrm{M})$. At the end of two elongation periods (90 d) the cotyledon survival percentage, SEC and multiplication rate (number of shoot at the end of subculture/ initial shoots explants) were determined.

\subsection{Rooting shoots and acclimatization of plants}

For rooting, elongated microshoots $(>10 \mathrm{~mm}$ ) grown on $1 / 2$ LPC were transferred to culture tubes with rooting medium LP supplemented with $10 \mu \mathrm{M}$ naphtalen acetic acid (NAA), $20 \mathrm{~g} \mathrm{~L}^{-1}$ glucose and $0.8 \%(\mathrm{w} / \mathrm{v})$ of Roko-Agar according to Amely Zavattieri (personal communication). This induction phase of adventitious root formation took place one week in the dark at $19{ }^{\circ} \mathrm{C}$ and another one with 16-h photoperiod under a photosynthetic photon flux of $100 \pm$ $5 \mu \mathrm{mol} \mathrm{m} \mathrm{m}^{-2} \mathrm{~s}^{-1}$ at the same temperature. After $2 \mathrm{wk}$, treated shoots were transferred to expression media LP with $10 \mathrm{~g} \mathrm{~L}^{-1}$ glucose but without regulators and were maintained in a growth chamber at $21 \pm$ $1{ }^{\circ} \mathrm{C}$ with the mentioned light conditions. Various macroelements strengths $(1,1 / 2$ or $1 / 4)$ in rooting and expression media were assayed. The percentage of survival, rooted shoots and the number of roots per shoot were recorded after $45 \mathrm{~d}$ on expression media.

After six weeks of culturing on expression medium, rooted shoots with $10 \mathrm{~mm}$ or longer roots were transferred to a sterile peat- perlite 1:4 (v/v) mixture and grown under high relative humidity (95\%) in a green house. After about $2 \mathrm{wk}$, the plants could be transferred to normal humidity conditions.

\subsection{Data analysis}

A completely randomized experimental design was applied and experiments were repeated at least three times. At least 30 explants 
Table I. Effect of different exposure time to BA $44.4 \mu \mathrm{M}$ on survival, percentage of cotyledons forming buds (CBF), buds per cotyledon and bud forming capacity (BFC) in Pinus pinea L. Isolated cotyledons were cultured $1 / 2$ LP with $44.4 \mu \mathrm{M} \mathrm{BA}$ and transferred to the same medium without growth regulators and activated charcoal ( $1 / 2$ LPC). Data was taken after 60 days on $1 / 2$ LPC. Values are means \pm SE $(n \geq 30)$. Significant differences $(\alpha=0.05)$ between incubation period are indicated by different letters.

\begin{tabular}{ccccc}
\hline Induction period $(\mathrm{d})$ & Survival $(\%)$ & CFB $(\%)$ & Buds per cotyledon $^{1}$ & BFC $^{2}$ \\
\hline 35 & $100 \mathrm{a}$ & $100 \mathrm{a}$ & $33.12 \pm 1.23 \mathrm{a}$ & $33.12 \mathrm{a}$ \\
16 & $100 \mathrm{a}$ & $96.66 \mathrm{a}$ & $29.06 \pm 0.95 \mathrm{a}$ & $28.08 \mathrm{a}$ \\
8 & $90.63 \mathrm{~b}$ & $90.85 \mathrm{a}$ & $10.58 \pm 0.26 \mathrm{~b}$ & $9.61 \mathrm{~b}$ \\
4 & $80.32 \mathrm{~b}$ & $90.05 \mathrm{a}$ & $6.82 \pm 0.23 \mathrm{c}$ & $6.14 \mathrm{~b}$ \\
2 & $44.55 \mathrm{c}$ & $45.49 \mathrm{~b}$ & $3.49 \pm 0.19 \mathrm{~d}$ & $1.58 \mathrm{c}$ \\
0 & $18.79 \mathrm{~d}$ & $0 \mathrm{c}$ & $0 \mathrm{e}$ & $0 \mathrm{~d}$ \\
\hline
\end{tabular}

${ }^{1}$ Excludes cotyledons without buds.

(cotyledons or shoots) per treatment were used. Data are presented as mean \pm standard error (SE). The statistical analysis of frequencies (e.g. \% cotyledons forming buds) were usually carried out with the $\chi^{2}$ test, except where indicated. Quantitative data (e.g. number of buds per cotyledon) were analyzed by non parametric tests. The Kruskall-Wallis test for $n$ independent group analyses was used, and the Mann-Whitney test for two independent group analyses. Differences were considered significant at the $5 \%$ level. All statistical tests were performed with STATISTICA ${ }^{\circledR}$ software.

\section{RESULTS AND DISCUSSION}

\subsection{Bud induction}

In order to study the correlation between cytokinin types and quantitative aspects of development, different cytokinins and concentrations were studied (Fig. 1). After $35 \mathrm{~d}$ of culture on bud induction medium, cotyledons were subcultured two times on growth-regulator free medium with activated charcoal $(1 / 2$ LPC) for bud growth. The induction of adventitious shoots on the cotyledons required the presence of cytokinin in the culture medium. Except for iPR and RZ, the other assayed cytokinins induced bud formation in cotyledons. The highest percentage $(100 \%)$ of cotyledons forming buds and the highest mean number of buds per cotyledon (data not shown) were obtained in BA treated cotyledons. The minimum concentration of assayed cytokinins $(0.4 \mu \mathrm{M})$ necessary to induce buds (CFB) was observed for BA and 9R-BA. Using m-T no morphogenic response was obtained at the low concentrations $(0.4$ and $1 \mu \mathrm{M}$ ) and it was necessary to apply $\geq 4.4 \mu \mathrm{M}$ in order to obtain bud induction. Both in $\mathrm{iP}$ and $\mathrm{Z}$-treated cotyledons $10 \mu \mathrm{M}$ and higher were needed to obtain a response.

$\mathrm{BA}$ and its riboside were the most efficient of the cytokinins assayed. In stone pine cotyledons, the effect of BA concentration and length of exposure on bud induction was already analysed by our group $[12,13,19]$ but the influence of these in the later shoot development was not studied previously. Bud induction was obtained when $1 / 2$ LP with $44.4 \mu \mathrm{M}$ BA was applied during various induction periods and consequently, this media was used as the bud induction medium (Tab. I). Significant differences in the $\mathrm{CFB}, \mathrm{BFC}$, survival percentage and

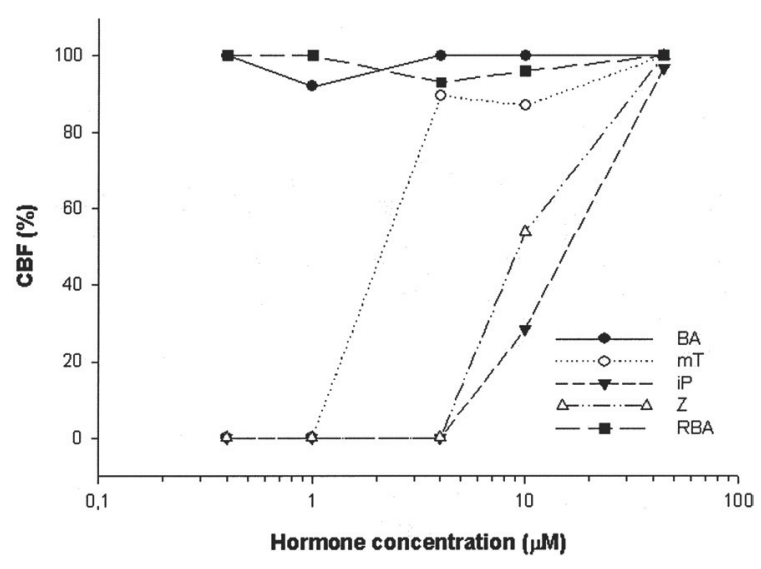

Figure 1. Percentage of cotyledons forming buds (CFB) in Pinus pinea $\mathrm{L}$. Cotyledons were cultured in vitro on $1 / 2 \mathrm{LP}$ medium with different cytokinins for $35 \mathrm{~d}$ and then transferred to $1 / 2$ LPC. Data were taken after 60 days of culture. Percentages have been transformed using arcsin transformation for statistical analysis. Two way analysis of variance (ANOVA) with type of $\mathrm{Ck}$ and concentration as the two factors tested, indicated that both were significant at $p \leq 0.05$ for percentage of cotyledons forming buds.

number of buds per cotyledon were observed depending on the BA-exposure time $(2,4,8,16$ or $35 \mathrm{~d})$ (Tab. I). A two-day treatment showed very low percentage of survival $(44.55 \%)$, CFB and buds per cotyledons (3.49 \pm 0.19$)$. Exposing cotyledons to BA for 4, 8, 16 or 35 d increased significantly the CFB. Explants cultured $35 \mathrm{~d}$ or $16 \mathrm{~d}$ in presence of BA showed the highest CFB ( $>95 \%$ ), but callus formation was also observed. When the induction period was reduced to 8 or $4 \mathrm{~d}$, CFB was not affected but a significantly decrease in the number of buds was observed. Among the exposure times examined, shoot development at the end of two subcultures on $1 / 2$ LPC was the greatest when the cotyledons were exposed to BA for 4 or $8 \mathrm{~d}$.

Explants cultured 35 or $16 \mathrm{~d}$ in presence of BA showed the formation of nodular primordia on the entire surface of cotyledons in contact with the medium, although shoot organogenesis was higher on the basal segment of the cotyledons for all treatments. However, few of these primordia developed into buds and shoots after transferring to $1 / 2$ LPC. This was 


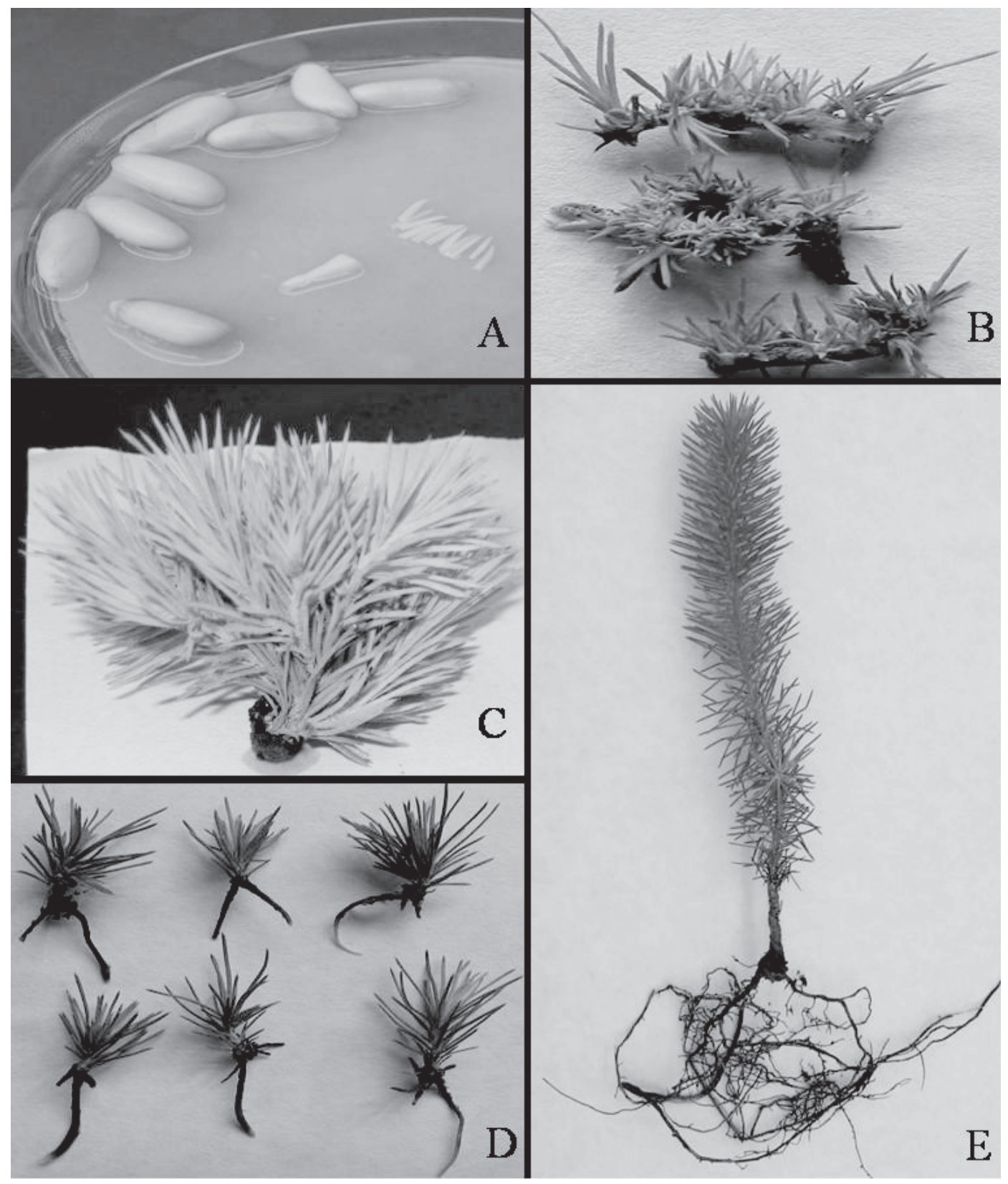

Figure 2. Adventitious shoot formation of Pinus pinea L. excised cotyledons. (A) Excised cotyledons from 0 d germinated embryos. (B) Adventitious buds in $4 \mathrm{~d}$ BA treated cotyledons after $35 \mathrm{~d}$ of culture. (C) Axillary shoots after 4 subcultures in $1 / 2$ LPC. (D) Rooted shoots excised from (C) after 4 wk in expression media. (E) A 1-year-old plantlet grown under greenhouse conditions. (A color version of this Figure is available at www.edpsciences.org/forest.)

presumably due to the proximity and competition among primordia. Buds were located along entire length of 4 and $8 \mathrm{~d}$ treated cotyledons (Fig. 2B). The lowest exposure time ( $2 \mathrm{~d}$ ) caused a redistribution of induced buds to the basal zone. Our data support the observations of Valdés et al. [19] and Sul and Korban [18]. Valdés et al. [19] suggested that a decrease of endogenous cytokinins levels may be involved in loss of shootforming ability in the apical portions of stone pine cotyledons. On the contrary, other studies in pines such as P. nigra [9] or $P$. ayacahuite [16], described the apical area of cotyledons as more organogenic. In general, like in other pines $[9,16]$, adventitious bud induction on excised cotyledons from stone pine ungerminated embryos was strongly influenced by the length of the exposure to growth regulators.

Although the number of buds formed in each cotyledon was lower in explants incubated for 4 or $8 \mathrm{~d}$ in $44.4 \mu \mathrm{M}$ BA than in explants cultured for 16 and $35 \mathrm{~d}$, the minimum induction period to obtain an optimal percentage, number of shoots 
Table II. Effect of different hormonal treatments on multiplication rate, shoot elongation capacity (SEC) and survival on S4 shoots of Pinus pinea $\mathrm{L}$. The isolated shoots were successively subcultured on $1 / 2 \mathrm{LP}$ with active charcoal $(1 / 2 \mathrm{LPC})$ or BA and AIB for $15 \mathrm{~d}$ and then transferred to $1 / 2$ LPC for $30 \mathrm{~d}$. Values correspond with two subcultures and are means $\pm \operatorname{SE}(n \geq 120)$. Significant differences $(\alpha=0.05)$ between hormonal treatments are indicated by different letters.

\begin{tabular}{|c|c|c|c|c|c|c|}
\hline \multicolumn{2}{|c|}{ Hormonal treatment } & \multicolumn{3}{|c|}{ First subculture (45d) } & \multicolumn{2}{|c|}{ Second subculture $(90 \mathrm{~d})$} \\
\hline & & Survival(\%) & Multiplication rate & SEC & Multiplication rate & SEC \\
\hline \multicolumn{2}{|l|}{$1 / 2 \mathrm{LPC}$} & $91.6 \mathrm{a}$ & $2.6 \pm 0.35 \mathrm{a}$ & $25.64 \mathrm{a}$ & $2.0 \pm 0.11 \mathrm{a}$ & $81.48 \mathrm{a}$ \\
\hline $\mathrm{BA}(\mu \mathrm{M})$ & $\mathrm{AIB}(\mu \mathrm{M})$ & & & & & \\
\hline 4.4 & 0 & $97.2 \mathrm{a}$ & $2.6 \pm 0.51 \mathrm{a}$ & $12.57 \mathrm{a}$ & $1.8 \pm 0.21 \mathrm{a}$ & $40.54 \mathrm{~b}$ \\
\hline 0.4 & 0 & $97.2 \mathrm{a}$ & $2.1 \pm 0.15 \mathrm{a}$ & $19.48 \mathrm{a}$ & $1.4 \pm 0.14 \mathrm{a}$ & $38.00 \mathrm{~b}$ \\
\hline 0.04 & 0 & $97.2 \mathrm{a}$ & $2.2 \pm 0.12 \mathrm{a}$ & $24.19 \mathrm{a}$ & $1.7 \pm 0.09 \mathrm{a}$ & $40.38 \mathrm{~b}$ \\
\hline 4.4 & 0.004 & $94.44 \mathrm{a}$ & $2.4 \pm 0.13 \mathrm{a}$ & $17.97 \mathrm{a}$ & $1.5 \pm 0.11 \mathrm{a}$ & $67.07 \mathrm{c}$ \\
\hline 4.4 & 0.04 & $94.44 \mathrm{a}$ & $2.3 \pm 0.14 \mathrm{a}$ & $14.61 \mathrm{a}$ & $1.8 \pm 0.25 \mathrm{a}$ & $37.31 \mathrm{~b}$ \\
\hline 4.4 & 0.4 & $97.2 \mathrm{a}$ & $2.6 \pm 0.23 \mathrm{a}$ & $26.75 \mathrm{a}$ & $1.6 \pm 0.20 \mathrm{a}$ & $71.42 \mathrm{c}$ \\
\hline
\end{tabular}

per cotyledon and highest survival index was 4 or $8 \mathrm{~d}$. These shorter periods are preferred because not only do they reduce the induction culture period, but also avoid callus formation and development of hyperhydric shoots, as was also observed in P. nigra [9] and P. ayacahuite [16]. In addition, a short bud induction period could lead to a higher rooting capacity as a result of a minor BA inhibitory influence in the rooting process. Following this protocol, an average of 100 shoots can be obtained per seed after $9 \mathrm{wk}$ in culture.

\subsection{Shoot development and axillary bud multiplication}

The multiplication phase, carried out with shoots separated from the cotyledonary explants and elongated by sequential subculturing on shoot growth medium, led to production of axillary shoots which were excised and subcultured. Shoot explants (S2) from C2 cotyledons showed the lowest survival percentage $(48.32 \%)$, multiplication rate $(1.4 \pm 0.065)$ and SEC (9.52) after $45 \mathrm{~d}$ on $1 / 2$ LPC and were discarded. After two subculture cycles (90 d), the survival percentage and multiplication rate were not significantly different between $\mathrm{S} 4$ and S8 shoots. On the contrary the SEC increase significantly in the second subculture of S4 shoots.

When BA and IBA were applied in shoot growth medium (Tab. II), the elongation index (SEC) was significantly lower than on $1 / 2$ LPC (81.5) and the multiplication rate was not significantly increased $(2.0 \pm 0.11)$. García-Ferriz et al. [6] describes this behaviour in $P$. pinea shoots when BA is applied in shoot development and multiplication stages, besides reporting the appearance of hyperhydric shoots. However, they did not observe any significant increase in the SEC index when shoots are cultured with activated charcoal. In our assay, although it could be influenced by the short BA induction period applied, the use of activated charcoal increases shoot development significantly during the elongation and multiplication stages (Tab. II). In fact, shoot elongation and multiplication rates were accelerated by subculturing successively on $1 / 2$ LPC medium. An average of $4.64 \pm 0.85$ axillary shoots and a 97.4 percentage of shoots higher than $10 \mathrm{~mm}$ were obtained after 4 subcultures ( $26 \mathrm{wk}$ ) on $1 / 2$ LPC (Fig. 2C). In addition, plagiotropic growth was never observed.

The development of nodular tissue (formed during bud induction) into shoots with primary needles was promoted by transferring cotyledonary explants to hormone free medium, as described previously for other pines such as $P$. canariensis [10]. Although its mechanism of action remains unclear, the cytokinin adsorption capacity of activated charcoal is well known, besides adsorbing other compounds like polyphenols, inorganic cations $\left(\mathrm{Cu}^{+}, \mathrm{Zn}^{+}\right)$or 5-hydroxymethyl furfural (inhibitory compound released from sucrose autoclaving) that inhibit shoot development [20,21], and specifically $P$. pinea rooting [2].

\subsection{Rooting shoots}

The data showed that the macro-salts dilutions both in induction and expression phase affected significantly the rhizogenic efficiency (Tab. III). Up to $68 \%$ of ryzogenesis was achieved when shoots were cultured on $1 / 2$ LP during root induction and expression. Roots appeared after 3-6 wk under these conditions (Fig. 2D). In all treatments, the roots obtained (1-3) were morphological normal. These data greatly improve the rhizogenesis efficiency, when compared to Capuana and Giannini [4], Gonzalez et al. [7] and Sul and Korban [18] which showed low levels (35, 15 and $15 \%$, respectively).

Because an additional 20 wk were required for shoot elongation and rooting, based on a $70 \%$ rooting success rate, at least 70 plantlets can be expected per seed after 29 wk. Besides, shoots can be micropropagated successively by subculturing on $1 / 2$ LPC.

Low levels of macronutrients in medium are beneficial for root formation in many plants. In general, it has been reported that the reduction of salts, particularly nitrogen, in the culture media seems to favour the adventitious rooting of cuttings $[11,15]$. Sriskandarajah et al. [17] reports that a reduction on the level of $\mathrm{NH}_{4} \mathrm{NO}_{3}$ in the MS culture media from 
Table III. Effect of the dilutions of macroelements on LP culture medium during the induction and expression rooting phases of Pinus pinea L. microshoots. Values are means $\pm \mathrm{SE}(n \geq 30)$. Significant differences $(\alpha=0.05)$ between dilutions are indicated by different letters.

\begin{tabular}{lccc}
\hline LP Macronutrients dilution & \multicolumn{2}{c}{ Rooting $\%$} & Number of roots/microshoot $^{1}$ \\
\hline Induction & Expression & $36.12 \mathrm{a}$ & 1.7 \\
\hline 1 & 1 & $47.09 \mathrm{~b}$ & 2.2 \\
1 & $1 / 2$ & $56.38 \mathrm{c}$ & 1.6 \\
1 & $1 / 4$ & $64.80 \mathrm{~d}$ & 1.9 \\
$1 / 2$ & 1 & $68.33 \mathrm{~d}$ & 2.8 \\
$1 / 2$ & $1 / 2$ & $38.12 \mathrm{a}$ & 2.5 \\
$1 / 2$ & $1 / 4$ & $31.78 \mathrm{e}$ & 2.5 \\
$1 / 4$ & 1 & $27.56 \mathrm{e}$ & 2.1 \\
$1 / 4$ & $1 / 2$ & $41.77 \mathrm{a}$ & 1.9 \\
\hline
\end{tabular}

${ }^{1}$ Excludes shoots without roots.

full strength to $1 / 4$ strength significantly increases the percentage rooting in several scion apple cultivars. Our results point that way but we obtain less rooting when the macronutrients strength was $1 / 4$. This phenomenon could be explained because LP levels of nitrogen are much lower than those present in MS and dilutions higher than $1 / 2$ would represent very low levels of nitrogen for $P$. pinea shoots to be rooted. In general, we showed that the macrosalts strength of culture medium affect significantly the rooting efficiency of stone pine microshoots and must be optimized.

For acclimatization experiments at least 100 microplants were transferred to a sterile peat-perlite $(1: 4 \mathrm{v} / \mathrm{v})$ mixture and grown under decreasing initially high relative humidity allowing its transfer to normal conditions two weeks later. Survival of microplants after two months in the nursery reached $98 \%$. No plagiotropic growth was observed and the plants showed a well developed root system capable of sustaining further shoot outgrowth (Fig. 2E). Our level of acclimatization is markedly higher than the only previous data reported by Capuana and Giannini [4] which showed a discrete level of survival (60\%).

The protocol presented here allows and greatly improves the method for plant regeneration in stone pine, when compared to Capuana and Giannini [4] Gonzalez et al. [7] and Sul and Korban [18]. This protocol is being applied successfully to produce and provide stone pine clonal plants obtained from selected seeds to the Programa de Mejora Genética del pino piñonero de Castilla y León (Spain).

Acknowledgements: The authors sincerely thank Jaime Menéndez Humara for the revising of the English language. Pablo Alonso and this work were supported by Ministerio de Ciencia y Tecnología de España (MCT-02-AGL-00867).

\section{REFERENCES}

[1] Aitken-Christie J., Singh A.P., Horgan K.J., Thorpe T., Explant developmental state and shoot formation in Pinus radiata cotyledons, Bot. Gaz. 146 (1985) 190-203.
[2] Arduini I., Godbold D.L., Onnis A., Influence of copper on root growth and morphology of Pinus pinea L. and Pinus pinaster Ait. Seedlings, Tree Physiol. 15 (1995) 411-415.

[3] Auer C.A., Motyka V., Brezinová A., Kamínek M., Endogenous cytokinin accumulation and cytokinin oxidase activity during shoot organogenesis of Petunia hybrida, Physiol. Plant. 105 (1999) 141-147.

[4] Capuana M., Giannini R., In vitro plantlets regeneration from embryonic explants of Pinus pinea L., In Vitro Cell Dev. Biol. Plant 31 (1995) 202-206.

[5] Cortizo M., Alonso P., Fernández B., Rodríguez A., Centeno M.L., Ordás R.J., Micrografting of mature stone pine (Pinus pinea L.) trees, Ann. For. Sci. 61 (2004) 843-845.

[6] García-Ferriz L., Serrano L., Pardos J.A., In vitro shoot organogenesis from excised immature cotyledons and microcuttings production in stone pine, Plant Cell Tissue Organ Cult. 36 (1994) 135-140.

[7] Gonzalez M.V., Rey M., Tavazza R., La Malfa S., Cuozzo L., Ancora G., Improvement of in vitro adventitious shoot formation on cotyledons of Pinus pinea L., HortScience 33 (1998) 749-750.

[8] Humara J.M., Lopez M., Ordás R.J., Agrobacterium tumefaciensmediated transformation of Pinus pinea L. cotyledons: an assessment of factors influencing the efficiency of uidA gene transfer, Plant Cell Rep. 19 (1999) 51-58.

[9] Lopez M., Pacheco J., Rodríguez R., Ordás R., Regeneration of plants from isolated cotyledons of salgareño pine (Pinus nigra Arn ssp. salzmannii (Dunal) Franco), In Vitro Cell Dev. Biol. Plant 32 (1996) 109-114.

[10] Martinez-Pulido C., Harry I.S., Thorpe T.A., In vitro regeneration of plantlets of Canari island pine (Pinus canariensis), Can. J. For. Res. 20 (1990) 1200-1211.

[11] Moe R., Andersen S., Stock plant environment and subsequent adventitious rooting, in: Davis T.D., Haissing B.E., Sankhla N. (Eds.), Adventitious root formation in cuttings, Dioscorides Press, Portland, OR, USA 1988, pp. 214-234.

[12] Moncaleán P., Alonso P., Centeno M.L., Rodríguez A., Fernández B., Cortizo M., Ordás R.J., Cytokinins and morphogenesis in P. pinea cotyledons, in: Espinel S., Barredo Y., Ritter E. (Eds.), Sustainable forestry wood products and biotechnology, DFA-AFA Press, Vitoria-Gasteiz 2003, pp. 71-77.

[13] Moncaleán P., Alonso P., Centeno M.L., Cortizo M., Rodríguez A., Fernández B., Ordás R.J., Organogenic responses of Pinus pinea L. cotyledons to hormonal treatments: BA metabolism and cytokinin content, Tree Physiol. 25 (2005) 1-9. 
[14] Oliveira P., Barriga J., Cavaleiro C., Peixe A., Potes A., Sustained in vitro root development obtained in Pinus pinea L. inoculated with ectomycorrhizal fungi, Forestry 76 (2003) 579-587.

[15] Ordás R.J., Rodríguez A., Rodríguez R., Sánchez R., Desarrollo de técnicas de cultivo "in vitro" para la micropropagación de variedades de manzana sidrera, Edafol. Agrobiotecnol. 43 (1985) 905-917.

[16] Saborio F., Dvorak W.S., Donahue J.K., Thorpe T.A., In vitro regeneration of plantlets from mature embryos of Pinus ayacahuite, Tree Physiol. 17 (1997) 787-796.

[17] Sriskandarajah S., Skirvin R.M., Abu-Qaoud H., The effect of some macronutrients on adventitious root development on scion apple cultivars in vitro, Plant Cell Tissue Organ Cult. 21 (1990) 185-189.
[18] Sul I.W., Korban S.S., Effects of salt formulations, carbon sources, cytokinins, and auxin on shoot organogenesis from cotyledons of Pinus pinea L., Plant Growth Regul. 43 (2004) 197-205.

[19] Valdés A.E., Ordás R.J., Fernández B., Centeno M.L., Relationships between hormonal contents and the organogenic response in Pinus pinea cotyledons, Plant Physiol. Biochem. 39 (2001) 1-8.

[20] Van Winkle S.C., Johnson S., Pullman G.S., The impact of Gelrite and activated carbon on the elemental composition of two conifer embryogenic tissue initiation media, Plant Cell Rep. 21 (2003) $1175-1182$

[21] Yasseen M.Y., Influence of agar and activated charcoal on uptake of gibberellin and plant morphogenesis in vitro, In Vitro Cell Dev. Biol. Plant 37 (2001) 204-205. 